\title{
Effect of Artemisia ciniformis Extract on Expression of NorA Efflux Pump Gene in Ciprofloxacin Resistant Staphylococcus aureus by Real Time PCR
}

\author{
Zeynab Ghomi ${ }^{1}$, Farzaneh Tafvizi ${ }^{* 1}$, Vahid Naseh $^{1}$, Iman Akbarzadeh ${ }^{2}$
}

1. Department of Biology, Parand Branch, Islamic Azad University, Parand, Iran

2. Department of Chemical and Petrochemical Engineering, Sharif University of Technology, Tehran, Iran

\section{ABSTRACT}

Background: Activity of norA efflux pump is one of the antibiotic resistance mechanisms in ciprofloxacin resistant Staphylococcus aureus. In this study, the effect of Artemisia ciniformis extract on reducing the expression of norA efflux pumps gene in ciprofloxacin-resistant Staphylococcus aureus isolates was studied.

Materials \& Methods: Ciprofloxacin resistant $S$.aureus isolates, were treated by different concentration of $A$. ciniformis extract. After extracting RNA and synthesizing cDNA, norA efflux pump expression was evaluated by Real Time PCR.

Results: There was significant decrease of norA efflux pump expression in ciprofloxacin-resistant $S$. aureus isolates treated by $A$. ciniformis extract $(P<0.05)$. Also, a different expression of norA efflux pump gene was reported.

Conclusion: It seems A. ciniformis extract as a natural inhibitor, had potential for suppression of norA efflux pump activity.

Keywords: Staphylococcus aureus, Ciprofloxacin, norA, Efflux Pump, Artemisia ciniformis

Received: 2019/10/2; Accepted: 2020/01/07; Published Online: 2020/03/14

\begin{tabular}{|c|c|c|}
\hline \multirow{2}{*}{\multicolumn{2}{|c|}{ Corresponding Information: }} & Farzaneh Tafvizi, 1. Department of Biology, Parand Branch, Islamic Azad University, Parand, Iran. \\
\hline & & Email: arzanehtafvizi54@gmail.com \\
\hline (c) (1) (8) & \multicolumn{2}{|r|}{$\begin{array}{l}\text { Copyright (C) 2020, This is an original open-access article distributed under the terms of the Creative Commons Attribution-noncommercial } 4.0 \text { International License which } \\
\text { permits copy and redistribution of the material just in noncommercial usages with proper citation. }\end{array}$} \\
\hline
\end{tabular}

Use your device to scan and read the article online

\section{Introduction}

Staphylococcus aureus is a pathogenic bacterium of the Micrococcus family, which is a common pathogenic bacterium in hospital infections $(1,2)$. It causes a wide range of diseases including skin infections, pneumonia and endocarditis (3). One of the opportunistic pathogenic agents of nosocomial infections is methicillin-resistant Staphylococcus aureus (MRSA). Resistance to antibacterial agents in MRSA strains has caused limitations in the treatment of diseases caused by this bacterium (4).

One of the most important mechanisms of antibiotic resistance in bacterial cells is the outflow pumps that cause antibiotic outflow from bacterial cells, which is observed in many clinical pathogens (8). Output carriers of antibiotics are divided into five main families based on the amino acid sequence. These families include the major facilitator superfamily (MFS), the Resistance-nodulation-division (RND), the small multidrug resistance (SMR), the ATP-binding cassette enzyme-linked family, and multiple antibiotics, and the extrusion antibiotic family (9).

One of the important mechanisms of antibiotic resistance in $S$. aureus is the presence of efflux pumps. NorA, norB and norC efflux pumps are found in drugresistant strains (19). Various studies have shown that norA is capable of pumping various compounds 
including hydrophobic fluoroquinolones such as norfloxacin, ciprofloxacin and ethidium bromide (22). There is a direct relationship between increased expression of norA efflux pump and increased resistance to fluoroquinolones. Inhibition of these systems can be a promising strategy to enhance the effectiveness of antibiotics (14).

Many studies have shown that a wide range of plant extracts may act against bacterial resistant mechanisms (15). Artemisia belongs to the family asteraceae, a small plant that grows in temperate regions. It has 34 species in Iran and is highly regarded in Iranian and Chinese traditional medicine. It has numerous biological properties including antibacterial, antifungal, antioxidant and anti-inflammatory (16).

The aim of this study was to investigate the effect of A. ciniformis extract on expression Efflux pump norA in clinical isolates of ciprofloxacin-resistant $S$. aureus, a prospective study in Iran which was not studied before.

\section{Materials and Methods}

This study was done using clinical samples collected in authors' previous study (18). Collecting clinical specimens, detecting ciprofloxacin-resistant $S$. aureus isolates, performing microbial susceptibility testing (antibiogram) by agar disk diffusion method, PCR detection of norA gene, and phenotypic evaluation of active efflux pump was as presented in previous study (18).

\section{Collecting and Extracting A. ciniformis}

The $A$. ciniformis was prepared from the Iranian Biological Resource Center and kept in optimum condition. To do the extraction, $40 \mathrm{~g}$ of the plant was first weighed and $300 \mathrm{~mL}$ of $80 \%$ ethanol was added to the plant and kept in a shaker system for $24 \mathrm{~h}$ (90 rpm). After $24 \mathrm{~h}$, it was filtered and placed in an incubator at $37^{\circ} \mathrm{C}$ to completely evaporate the alcohol.

\section{Determination of Minimum Inhibitory Concentration (MIC) of Plant Extract}

MIC experiments were performed according to the dilution method in the microplate for the extract. MIC was performed three times by microdilution method on 96 well plates. The extract was poured into wells at concentrations of 15.6 to $1000 \mu \mathrm{g} / \mathrm{mL}$ and with
Mueller Hinton Broth (MHB) it reached to the concentration of $195 \mu \mathrm{L}$. All wells were added with 5 $\mu \mathrm{L}$ of microbial culture of isolates at half McFarland concentration. The MIC value was considered as the lowest inhibitory concentration of bacterial growth. It should be noted that wells containing non-extracted bacteria were considered as negative controls and wells containing standard bacteria $S$. aureus ATCC 25923 and extracts were considered as positive controls to determine MIC concentration.

\section{Extraction of RNA from Staphylococcus aureus Treated with subMIC Extract}

Bacterial cell lysis and RNA extraction were performed using RNX solution (Sinagen) according to the protocol. The cDNA construct was performed according to the Revert AidTM First Strand cDNA Synthesis Kit (Fermentas). The gmk gene (guanylate kinase) was used as the reference gene. The primers of the gmk and norA genes are presented in Table 1.

Real-time PCR reaction in the final volume of $25 \mu \mathrm{L}$ was optimized as follows: $12.5 \mu \mathrm{L}$ of SYBR TM (2X) Master Mix (Takara Company), $1 \mu \mathrm{L}$ of 5 pmol primer (Takapoo Biol.), $9.5 \mu \mathrm{L}$ of deionized water and $1 \mu \mathrm{L}$ cDNA template (100 ng). Thermal program was performed as follows with Bioneer exicycler 96: Primary denaturation of DNA template was performed at $95^{\circ} \mathrm{C}$ for $10 \mathrm{~min}$, and the second step alternately was performed during 40 cycles at $95^{\circ} \mathrm{C}$ for 20 seconds and at $61^{\circ} \mathrm{C}$ for 40 seconds and $72^{\circ} \mathrm{C}$ for 20 seconds.

\section{Data Analysis}

Statistical calculations were performed using Graphpad Prims ver.6 software and the results were analyzed by one way ANOVA. The difference of target genes expression between control and treated samples was calculated by Tukey's HSD post-hoc test. Data were presented as mean \pm standard deviation (SD) and $\mathrm{P}<0.05$ was considered significant. Real time $\mathrm{PCR}$ data analysis was performed based on the comparison of the threshold cycle with the following formula:

$\Delta \mathrm{Ct}=\mathrm{Ct}$ target-Ct reference

$\Delta \Delta \mathrm{Ct}=\Delta \mathrm{Ct}$ test sample $-\Delta \mathrm{Ct}$ control sample

Relative expression: $2^{-\Delta \Delta \mathrm{ct}}$

Table 1. Primers used in this study

\begin{tabular}{|c|c|c|}
\hline primers & sequences & PCR products (bp) \\
\hline norA-F & 5'ATCGGTTTAGTAATACCAGTCTTGC3' & \multirow{2}{*}{112} \\
\hline norA-R & 5'GCGATATAATCATTTGAGATAACGC3' & \\
\hline gmk-F & 5'TATCAGGACCATCTGGAGTAGG3' & \multirow{2}{*}{188} \\
\hline gmk-R & CATCAACTTCACCTTCACGC & \\
\hline
\end{tabular}




\section{Results}

MIC Results of Artemisia ciniformis Extract Against Ciprofloxacin-resistant Strains

According to the findings of the previous study, out of 250 clinical specimens, 50 isolates of Staphylococcus aureus were isolated and antibiotic susceptibility results showed that $68 \%$ of the samples (34 samples) were methicillin resistant and $24 \%$ of them ( 12 samples) were ciprofloxacin resistant and none of the samples were vancomycin resistant (18).

Ciprofloxacin-resistant $S$. aureus positive isolates were affected by concentrations of 15-1.6.6 $\mu \mathrm{g} / \mathrm{mL}$ of the plant extract over a 24-hour period. The results showed that different strains had a range of MIC of 31.55-500 $\mu \mathrm{g} / \mathrm{mL}$ (Table 2).

The graphs of the amplification of norA and gmk genes are shown in Figures 1 and 2. Specific amplification of the target gene fragments, primers not pairing, and no amplification of non-specific fragment for each gene were determined using the melting curve (1-2)The results showed that the expression of norA gene was significantly decreased compared to the reference gene $(g m k)$ after treatment with the plant extract. The highest decrease in norA gene expression was observed in isolate 6 and the lowest decrease in gene expression was observed in isolate 5 . The results are shown in Figure 3.

Table 2. Determination of MIC of plant extract in different strains.

\begin{tabular}{|c|c|}
\hline Isolate number & MIC $(\mu \mathrm{g} / \mathrm{mL})$ \\
\hline 1 & 62.5 \\
\hline 2 & 125 \\
\hline 3 & 31.2 \\
\hline 4 & 250 \\
\hline 5 & 500 \\
\hline 6 & 15.6 \\
\hline 7 & 62.5 \\
\hline 8 & 31.2 \\
\hline 9 & 125 \\
\hline 10 & 500 \\
\hline 11 & 31.25 \\
\hline 12 & 250 \\
\hline ATCC 35556 & 500 \\
\hline
\end{tabular}

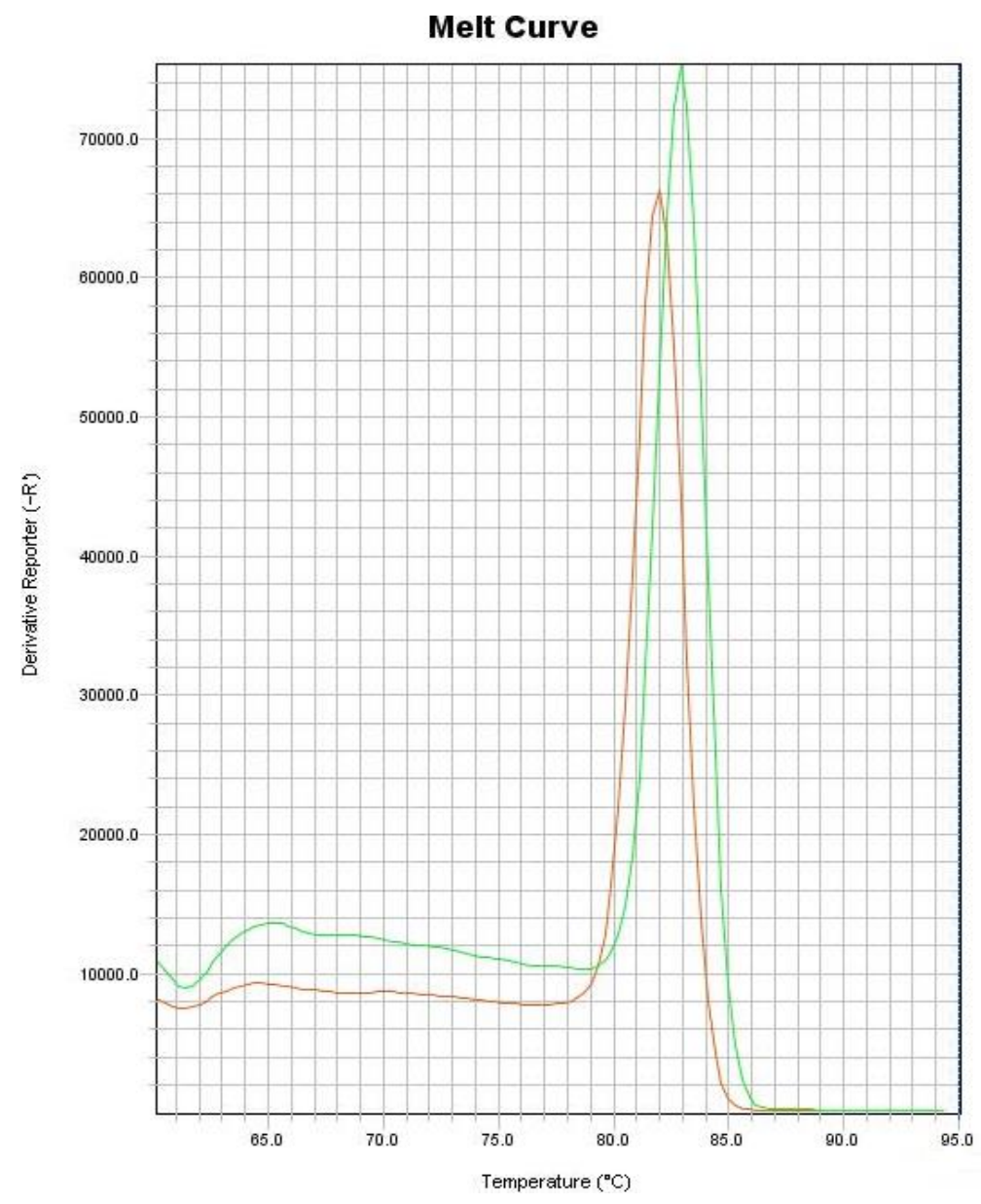

Figure 1. Diagram of melting curves of norA genes and gmk genes. 


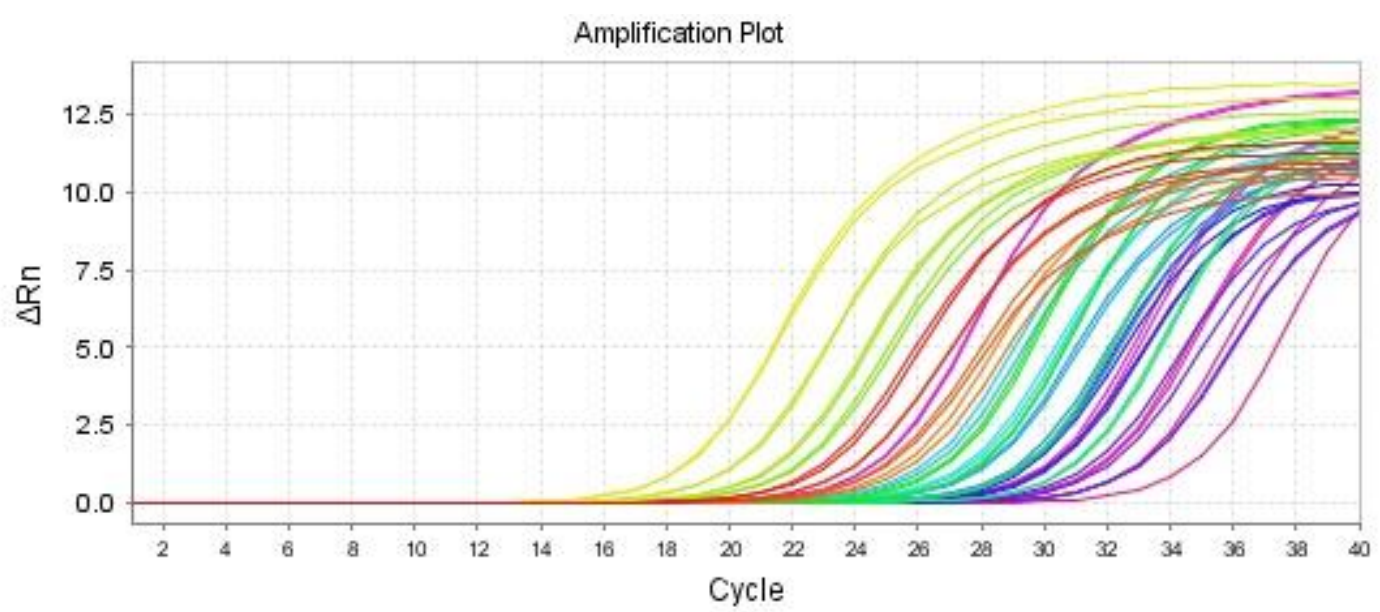

Figure 2. Amplification plot of norA and gmk gene in bacterial cells treated with extract.

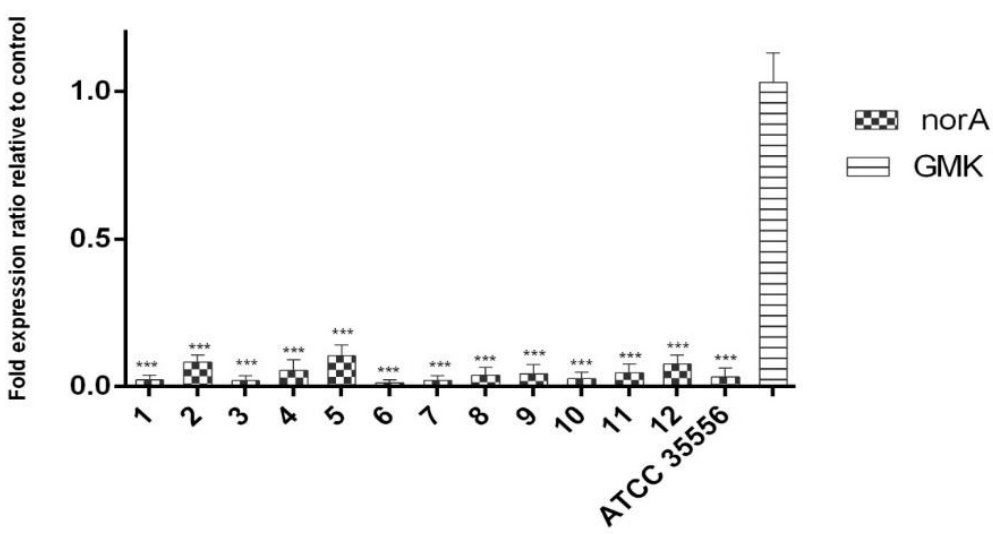

Figure 3. NorA gene expression in extract-treated strains.

\section{Discussion}

Since ancient times, medicinal plants have been used clinically as important sources of secondary metabolites (terpenoids, phenolic compounds and alkaloids). These plants can directly or indirectly affect the activity of efflux pumps. Recently, the use of herbal compounds and plant extracts as an alternative to antibiotics has received much attention (26). The difference in the effect of plant extracts on bacteria depends on various factors. In general, plant compounds exert their antimicrobial activity through a variety of mechanisms (27).

Due to their antibacterial potential, the use of herbal extracts can be an effective, low cost and affordable method to reduce antibiotic resistance in a wide range of hospital opportunistic bacteria (28).

The results of our study showed that $A$. ciniformis extract was able to significantly reduce norA gene expression in ciprofloxacin resistant strains. It should be noted that different expression of norA gene was observed in the resistant strains and in the more resistant strains a higher relative expression of the norA gene was observed.

Flavinoid sarothrin extracted from Alkann orientalis leaves and flowers inhibited norA efflux pump activity and inhibited the growth of Mycobacterium smegmatis and S. aureus (28).

The results of the study by Kalia et al. showed that capsaicin decreased the MIC of ciprofloxacin for $S$. aureus SA-1199B (norA overproducing), SA-1199 (wild-type). Increased susceptibility of $S$. aureus to ciprofloxacin was observed. This study showed that capsaicin not only decreased the efflux pump activity but also decreased the attack of Staphylococcus on macrophages (29).

Studies have shown that the extract and compounds of Olympicin A, 5,7-dihydroxy-6- (2-methylbutanoyl) 8- (3-methylbut-2-enyl) -4-phenyl-2H-chromen-2-one, Karavilagenin $\mathrm{C}$ and Ailanthoidiol, Boeravinone B from aerial parts of Hypericum olympicum L., flowers of Mesua ferrea L., aerial parts of Momordica balsamina L., root of Zanthoxylum capense and Boerhavia diffusa 
inhibited and decreased activity of norA efflux pump. In other words, they had an Efflux pump inhibitor (EPI) (30-34).

This study was in line with other studies showing that $A$. ciniformis reduced norA gene expression in efflux pumps in $S$. aureus. Decreased norA gene expression leads to poor performance of these pumps and prevents overflow of antibiotics and other disinfectants and pharmaceuticals. Therefore, this plant can be used as an appropriate antibacterial drug and, on the other hand, it is recommended with regard to its antiviral resistance, other efflux studies and antiviral antibiotic resistance.

\section{Acknowledgment}

The authors would like to acknowledge the laboratory of Islamic Azad University.

\section{Conflict of Interest}

Authors declared no conflict of interests. 


$$
\begin{aligned}
& \text { مجله ميكروبشناسى يزشكى ايران }
\end{aligned}
$$

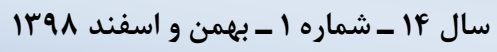

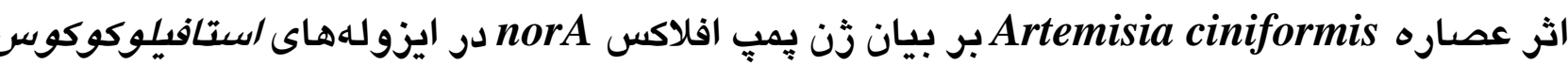

\title{
اورئوس مقاوم به سييروفلوكساسين توسط Real Time PCR
}

\author{
زينب قمى'، فرزانه تفويضى '“، وحيد ناصح '، ايمان اكبرزاده'

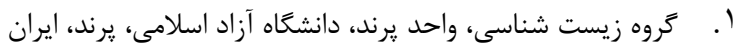

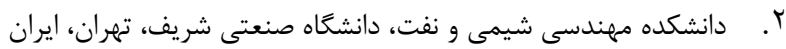

\begin{abstract}
جكسيله

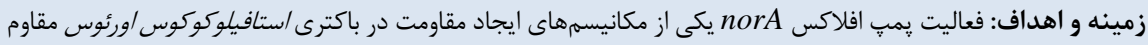

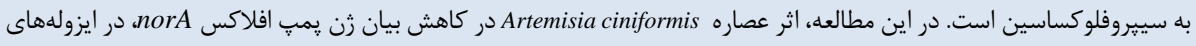

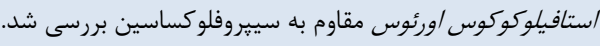

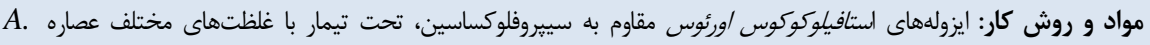

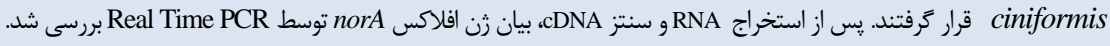

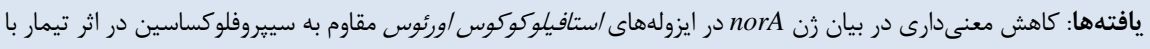

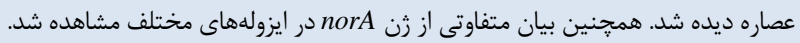

نتيجه كيرى: به نظر مىرسد عصاره A. ciniformis به عنوان مهاركنندة طبيعى، قادر به مهار و كاهش فعاليت يمب افلاكس norA است.

كليد وازهها: استافيلوكوكوس /ورئوس، سييروفلوكساسين، يمب افلاكس، Artemisia ciniformis ، norA

كبى رايت (؟ مجله ميكروب شناسى بزشكى ايران: دسترسى آزاد؛ كبى بردارى، توزيع و نشر براى استفاده غيرتجارى با ذكر منبع آزاد است.
\end{abstract}

اطلاعات مقاله

تاريخجٌهُ مقاله

دريافت: •|

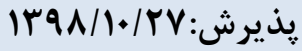

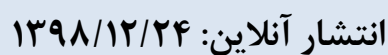

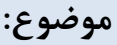

ميكروبش مؤناسى مولكولى

نويسندهُ مسئول:

فرزانه تفويضى، گروه زيست شناسى، واحد

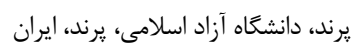

ايميل:

farzanehtafvizi54@gmail.com

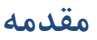

از مكانيسمهاى مهلم و اصلى ايجاد كننده مقاومت باكتريايى

استافيلوكوكوس ائوروس (Staphylococcus aureus)،

نسبت به آنتىبيوتيكها، مىتوان به غير فعال كردن دارو با استفاده

باكترى یاتوزن از خانواده ميكروكوكاسه است كه يك باكتوى

از آنزيمها، اصلاح هدف، تغيير در دسترسى به هدف از طريق خروج

بيمارىزاى شايع درعفونت هاى بيمارستانى به شمار مىرود (ا، ب).

دارو، كاهش جذب و ممانعت از تجمع دارو در درون سلول به وسيله

اين باكترى سبب بروز طيف وسيعى از بيمارىهاى مختلف

سيستمهاى افلاكس اشاره كرد (Y، V).

يكى از مهرمترين مكانيسمهاى مقاومت در برابر آنتىبيوتيكها در سلول باكترى، يمٍهای خروجى هستند كه

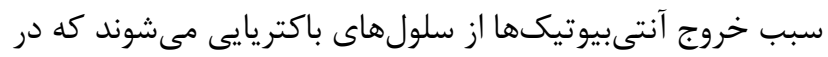
بسيارى از زاتوزنهاى بالينى مشاهده مىشود (1).. حاملهاى خروجى آنتىبيوتيكها براساس توالى آمينواسيدها به ينج خانواده

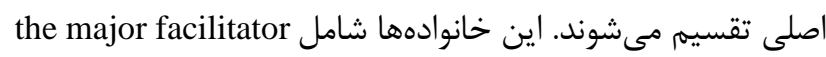
the Resistance-nodulation-division ،superfamily (MFS)
از جمله عفونتهاى يوستى، ينومونى و اندوكارديت مىشود (ب). يكى از عوامل فرصت طلب بيمارىزاى بيمارستانى، استافيلوكوكوس اورئوس مقاوم به متىسيلين (MRSA) است. ايجاد مقاومت به عوامل ضد باكتريايى در سويههاى MRSA، موجب بروز محدوديتهايى در درمان بيمارىهاى ناشى از اين باكترى شده است (F). يكى از داروهاى مناسب و جايخزين براى

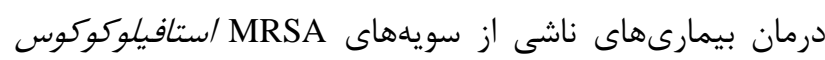
اورئوس، داروى سييروفلوكساسين است (ه). 
جدايههاى /ستافيلوكوكوس /ورئوس مقاوم به سييروفلوكساسين،

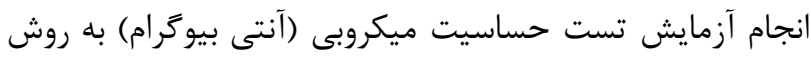
ديسك ديفيوزن آكار، شناسايى زن norA توسط PCR فنوتيجى وجود پِيٍ افلاكس فعال در مطالعه قبلى نويسندًان، ارايه

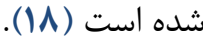

در مطالعه حاضر از روش Real Time PCR براى بررسى اثر عصارة گياه بر روى بيان زن norA ، به شرح ذيل استفاده شد.

\section{جمع آورى كياه A. ciniformis و عصارهگيرى}

كياه A. ciniformis از مركز ذخاير زيستى و زنتيكى ايران با كدهربار يمى IBRC1000652 تهيه شد و در شرايط بهينه و مناسب

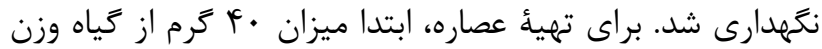

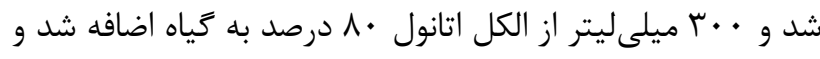

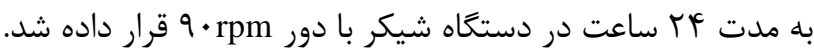
بعد از F ب ساعت از كاغذ صافى و فيلتر سر سرنگ براى فيلتر كردن

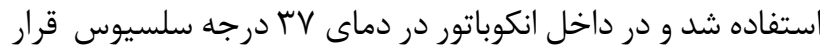
داده شد تا الكل آن بهطور كامل تبخير شود دانور درداي

\section{Minimum (MIC) تعيين حداقل غلظت مهارى} Inhibitory Concentration

آزمايش MIC به روش رقيقسازى در ميكرويليت براى

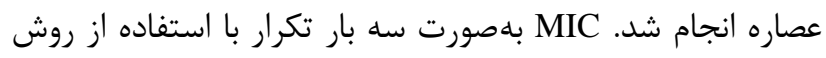
ميكرودايلوشن در يليتهاى 99 خانهاى انجام شد. عصاره در

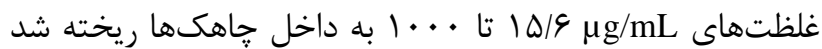
و با محيط كشت مولر هينتون براث (MHB) تا حجم 190

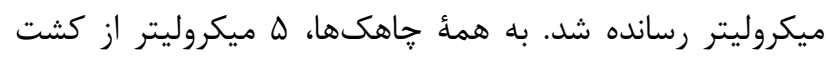

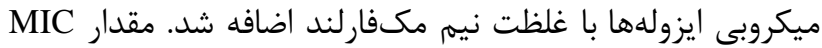
بهاعنوان كمترين غلظت مهار كننده رشد باكترى محسوب مى شود.

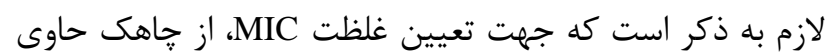

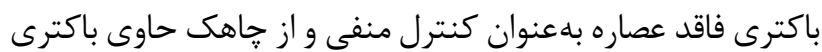
استاندارد /ستافيلوكوكوس /ورئوس ATCC 25923 و عصاره بهنوان كنترل مثبت استفاده شد.

\section{استخراج RNA از باكترى استافيلوكوكوس اورئوس}

تيمار شده با غلظت subMIC عصاره

ليز سلولهاى باكتر يايى با استفاده از محلول RNX (سينازن)

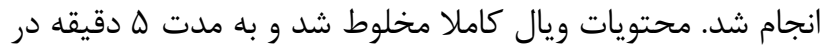

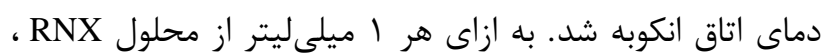

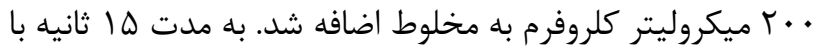

the ATP- ،(SMR) the small multidrug resistance ،(RND) binding cassette enzyme-linked

اكستروزن هستند (9).

انتشار داروها از باكترىهاى گرم مثبت عمدتا توسط يك كانال

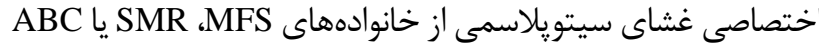

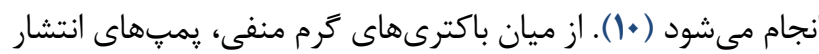
جندَانه رايج هستند كه متعلق به خانوادههاى RND و SMR هستند (II). آناليز انتقالدهندههاى آنتىبيوتيك در حال حاضر بلهور كستردهاى مورد بررسى قرار گرفته است (r) (I). با اين حال،

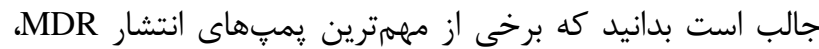

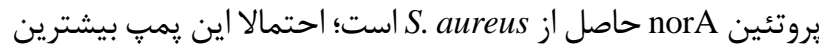

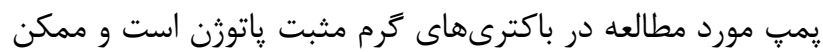
است مسئول حداقل • 1\% از مقاومت ضد باكترى در MRSA باشد (با). مهار اين سيستمها مىتواند يك راهكار نويدبخش براى تقويت اثر بخشى آنتىبيوتيكها باشد (If). بسيارى از مطالعات نشان دادهاند كه طيف كسترداى از عصارههاى كياهى ممكن است در مقابل مكانيسمهاى مقاوم به

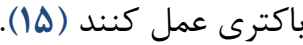

جنس Artemisia (درمنه) متعلق به خانواده asteraceae

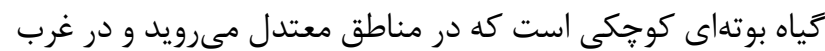
امريكا، افريقاى جنوبى و امريكاى جنوبى يراكنده است. اين جنس

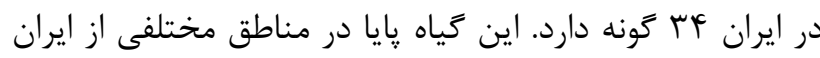

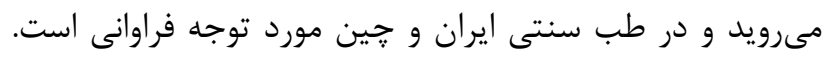
اغلب تونههاى اين كياه براى درمان ورم معده استفاده مىشوند علاوه بر آن داراى خواص بيولوزيكى متعددى جون خواص خداص ضد باكتريايى، ضدقارجى، آنتىاكسيدانى و ضدالتهابى هستند (1) (1). Artemisia ciniformis غرمان آباد در اصفهان، استان خراسان، در شمال شرقى ايران

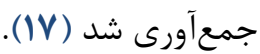

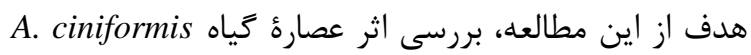

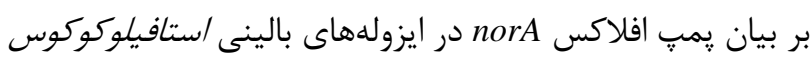
اورئوس مقاوم به سييروفلوكساسين است كه تاكنون مطالعهاى بئي درباء آن در ايران صورت نكرفته است.

$$
\text { مواد و روشها }
$$

اين مطالعه در راستاى مطالعهُ قبلى و از نمونههاى بالينى جمعآورى شده در مطالعهاى كه توسط نويسندكان انجام شده بود،

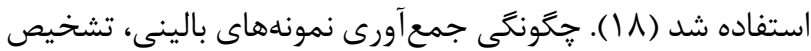


بلافاصله ميكروتيوبها به يخ انتقال يافت و مواد زير به هر تيوب اضافه شد. ساخت مولكولهاى DNA مكمل باكيت Revert ،Fermentas) AidTM First strand cDNA Synthesis Kit ليتوانى) انجام گرفت كه در آن مخلوط واكنش حاوى ه ميكروليتر

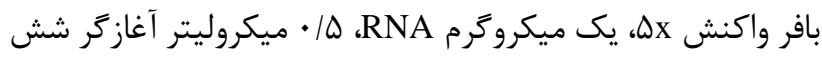
نوكلئوتيدى تصادفى، يك ميكروليتر مخلوط داكسى نوكلئوتيد

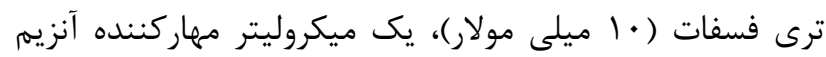
RNase

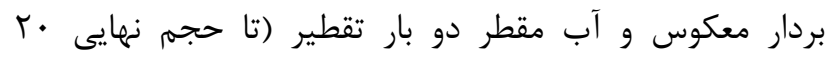

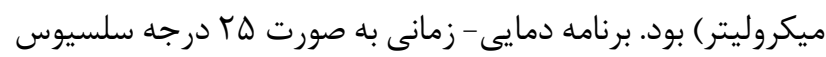

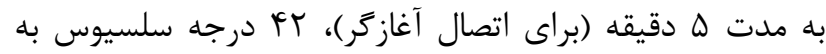

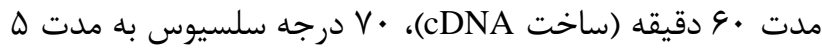

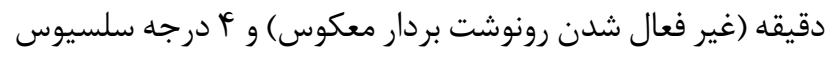
به مدت ه دقيقه انجام كرفت. انكوباسيون مخلوط واكنش به مد مدات

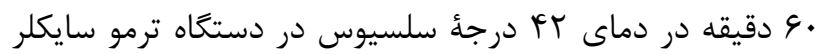

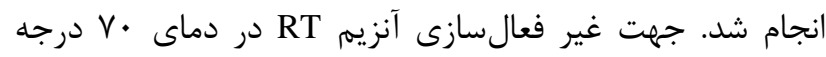

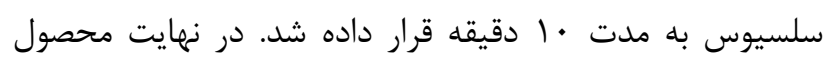

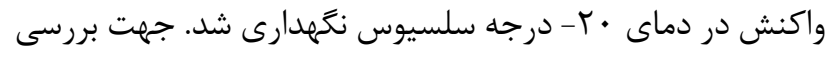

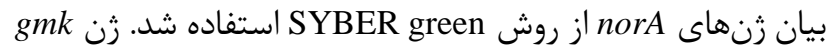

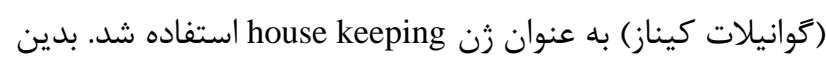
منظور ثرايمرهاى زنهاى gmk و norA در جدول ا ارايه شده

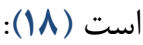

واكنش Real time PCR در حجم نهايى فا ميكروليتر به

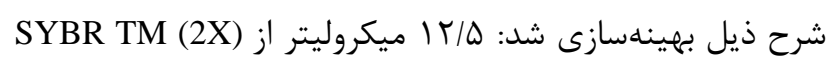
Master Mix (Takara Company)

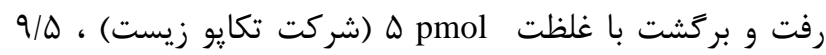

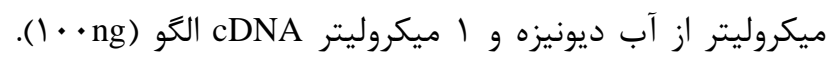

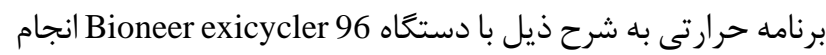

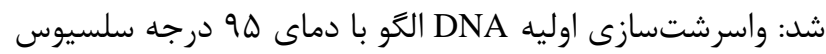

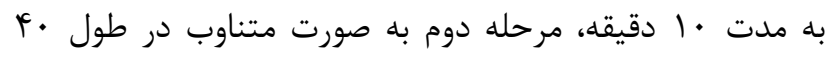

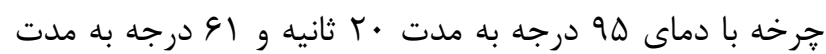

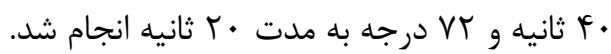

\section{تجزيهوتحليل آمارى دادهها}

Graphpad Prims محبات آمارى با استفاده از نرم افزار

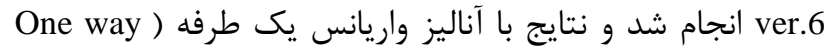

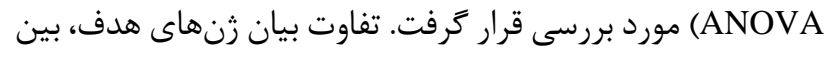
نمونهاى كنترل و تيمار شده با روش آمارى - Tukey،s HSD post
تكان شديد مخلوط همكن شد (در اين مرحله نبايد از ورتكس استفاده شود). محلول شيرى رنغ حاصل شد كه نشانه دناتوره

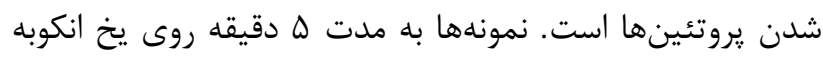

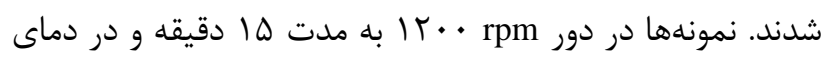

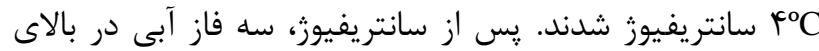

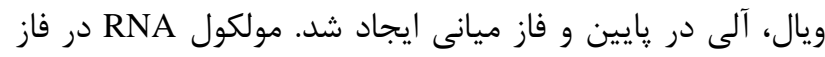

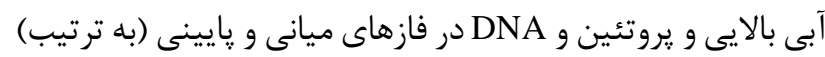

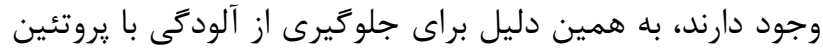

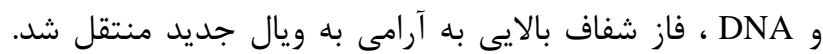

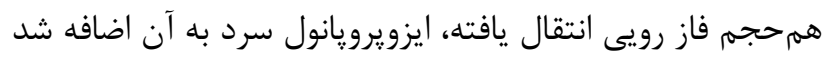

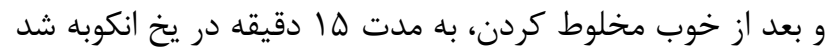

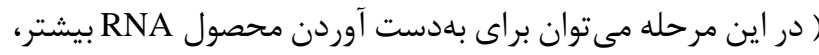

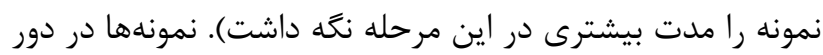

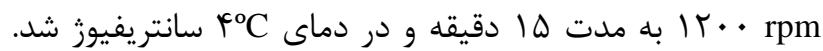

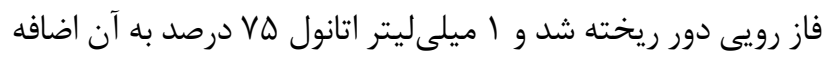

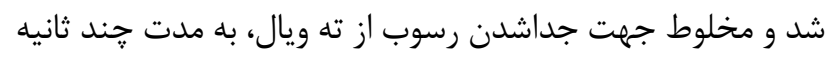

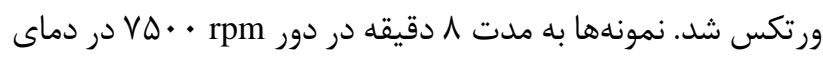
مال

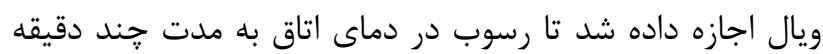

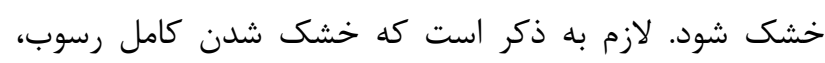

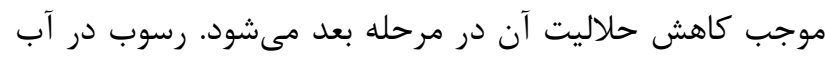

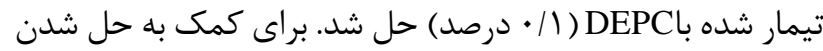

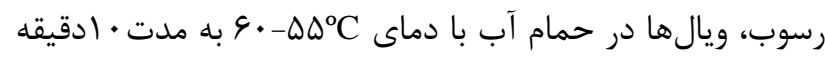

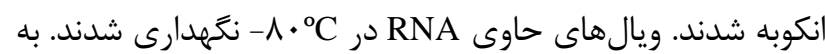
منظور عدم آلودگى ناشى از وجود DNA سلول در ادامه كار، قبل

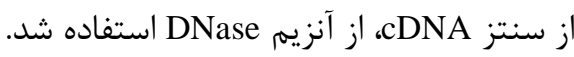

به منظور ساخت cDNA از روى RNA استخراج شده، يس

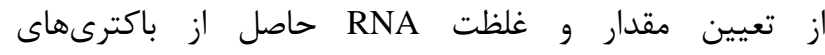
استافيلوكوكوس /ورئوس مقاوم به سييروفلوكساسين مجاور شده با باريات

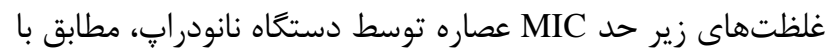
كيت ساخت ( Revert AidTM First Strand cDNA Synthesis Fermenta Kit

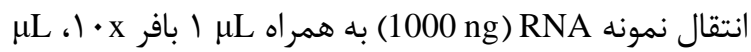
ا آنزيم DNase و آب تا حجم بL • • به يك ميكروتيوب ها.

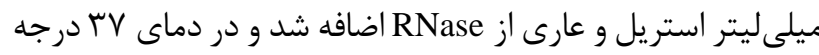

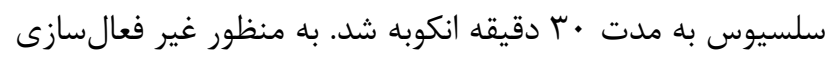

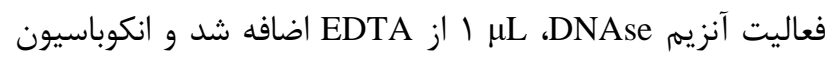
در دماى 9 9 درجأ سلسيوس به مدت • ا دقيقه انجام كرفت. 
بافتهها

نتايج MIC عصاره گياه Artemisia ciniformis عليه

\section{سويه هاى مقاوم به سييروفلوكساسين}

با توجه به يافتههاى مطالعأ قبلى، از ميان • له نمونه بالينى، تعداد · ه ايزوله /ستافيلوكوكوس /ورئوس جداسازى شد و نتايج

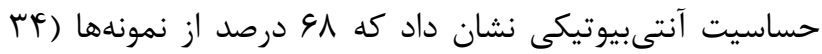
نمونه) مقاوم به متىسيلين و از ميان اينها F ب درصد (Y ( نمونه) مقاوم به سييروفلوكساسين بودند. هيجكدام از نمونهها مقاوم به

$$
\text { ونكومايسين نبودند (1) (1). }
$$

ايزولههاى مقاوم به سييروفلوكساسين استافيلوكوكوس

اورئوس مثبت تحت تاثير غلظتهاى بg/mL

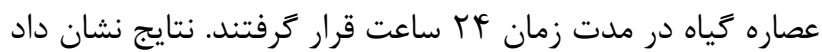
كه سويههاى مختلف داراى محدوده اى از

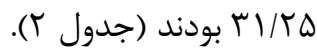

mean士standard محاسبه شد. اطلاعات به صورت hoc test deviation (SD) گرفته شد. آناليز دادههاى Real Time PCR بر اساس مقايسُٔ جرخهُ آستانه انجام شد. در اين مطالعه، اختلاف جرخههاى آستانٔ

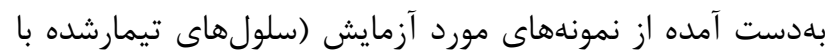
عصاره) و نمونههاى كنترل (سلولهاى تيمار نشده با عصاره)

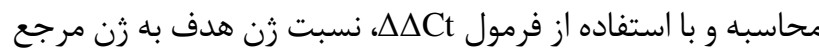
از طريق (gmk) شرح زير است:

$\Delta \mathrm{Ct}=\mathrm{Ct}$ target-Ct reference

$\Delta \Delta \mathrm{Ct}=\Delta \mathrm{Ct}$ test sample $-\Delta \mathrm{Ct}$ control sample

Relative expression: $2^{-\Delta \Delta \mathrm{Ct}}$

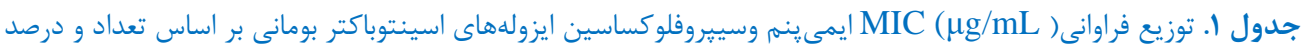

\begin{tabular}{|c|c|c|}
\hline نام برايمر & توالى برايمر & سايز قطعات (bp) \\
\hline norA-F & 5'ATCGGTTTAGTAATACCAGTCTTGC3' & \multirow{2}{*}{$11 \%$} \\
\hline norA-R & 5'GCGATATAATCATTTGAGATAACGC3' & \\
\hline gmk-F & 5'TATCAGGACCATCTGGAGTAGG3' & \multirow{2}{*}{$1 \wedge \Lambda$} \\
\hline gmk-R & CATCAACTTCACCTTCACGC & \\
\hline
\end{tabular}

جدول r. تعيين MIC عصاره گياه در سويdهاى مختلف.

\begin{tabular}{|c|c|}
\hline شماره ايزوله & MIC $(\mu \mathrm{g} / \mathrm{mL})$ \\
\hline 1 & ST/D \\
\hline$r$ & ITD \\
\hline$r$ & rו/ \\
\hline p & $r \Delta$. \\
\hline$\Delta$ & $\Delta . \cdot$ \\
\hline 9 & $10 / 9$ \\
\hline$v$ & ST/D \\
\hline$\wedge$ & $r / / r$ \\
\hline 9 & $1 T \Delta$ \\
\hline 1. & $\Delta .$. \\
\hline 11 & $r ו / r \Delta$ \\
\hline ir & $r \Delta$. \\
\hline ATCC 35556 & $\Delta \cdot \cdot$ \\
\hline
\end{tabular}

بررسى بيان زن norA در سويههاى مقاوم به سييروفلوكساسين در غلظتهاى subMIC از عصاره بيان نسبى زن مorA در ايزولههاى مقاوم به سييروفلوكساسين توسط روش Real Time PCR مورد مطالعه قرار

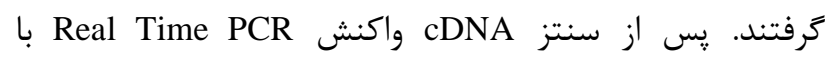
يرايمرهاى اختصاصى زن norA و gmk صورت زرفت. نمودار حاصل از تكثير زنهاى مورد نظر در شكلهاى اوr نشان داده

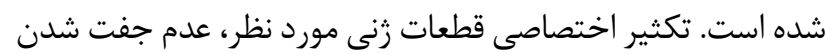
يرايمرها و عدم تكثير قطعات غيراختصاصى براى هر زن با استفاده از منحنى ذوب تعيين شد (1-Y). زن norA داراى نمودار ذوب

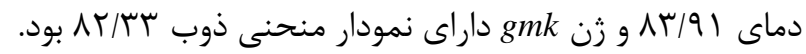


بيشترين كاهش بيان زن norA در ايزوله 9 (1 • • •) و كمترين كاهش بيان زن در ايزوله ه (9 • / •) ديده شد (جدول س). نتايج

در شكل r نمايش داده شده است.
نتايج نشان داد كه بيان زن norA نسبت به زن مرجع (gmk) يس از تيمار با عصارة گَياه كاهش معنى دار و جشمخيرى نشان داد. البته ميزان كاهش بيان متفاوتى در سويههاى مختلف ديده شد.

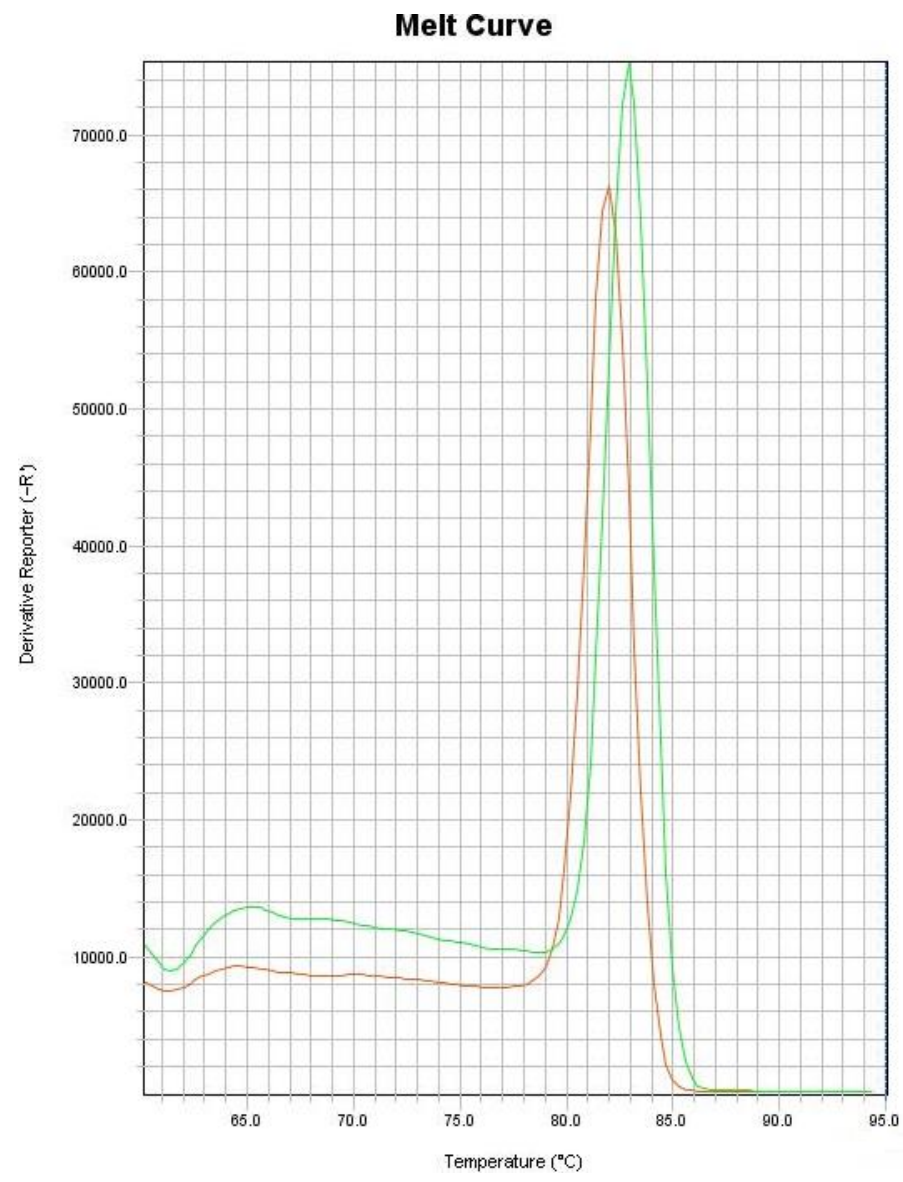

شكل ا. نمودار منحنى ذوب ثنهاى norA و gmk.

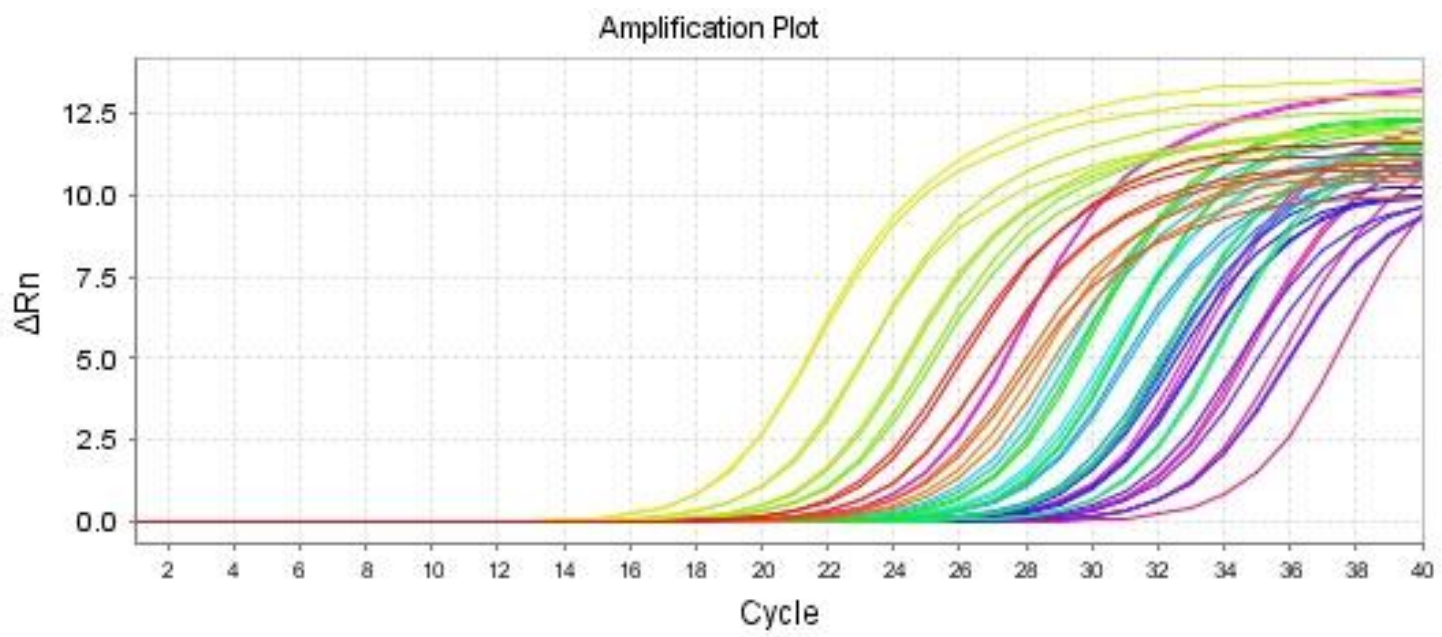

شكل r. نمودار تكثير زنهاى norA و gmk در باكترىهاى تيمار شده با عصاره. 
جدول س. نتايج بيان ثن norA در سويههاى مختلف مقاوم به سييروفلوكساسين.

\begin{tabular}{|c|c|c|c|c|c|c|}
\hline \multirow[b]{2}{*}{ شماره سويه } & \multicolumn{2}{|c|}{ تيمارنشده با عصاره } & \multicolumn{2}{|c|}{ تيمار شده با عصاره } & \multirow[b]{2}{*}{ تغيير بيان زن ica } & \multirow[b]{2}{*}{$\begin{array}{c}\text { GMK } \\
\text { Gيزان بيان }\end{array}$} \\
\hline & ميانگين GMK ct & ميانگين ica ct & ميانگين GMK ct & ميانكين ica ct & & \\
\hline 1 & $1 / 1 /$ & $r \cdot / \Lambda$ & $19 / \mathrm{V}$ & T\&/V & 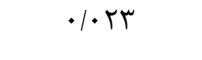 & $\downarrow$ \\
\hline$r$ & $19 / 0$ & $19 / 90$ & $r \cdot / r$ & Tr/g & $\cdot / \cdot \wedge \Delta$ & $\downarrow$ \\
\hline$r$ & 19 & $r \cdot / F$ & $r \cdot / r$ & $r \varepsilon / 90$ & $.1 \cdot 14$ & $\downarrow$ \\
\hline f & $11 / 9$ & $r \cdot 1 \Delta \omega$ & $19 / 9$ & $r \Delta / r \omega$ & $\cdot / \cdot \Delta 1$ & $\downarrow$ \\
\hline$\Delta$ & $19 / r$ & $11 / 90$ & $19 / 1$ & $T r / T$ & $\cdot 11 \cdot 9$ & $\downarrow$ \\
\hline 9 & $19 / V$ & $19 / V \Delta$ & $r \cdot / F$ & $T V / T$ & $\cdot / \cdots \wedge$ & $\downarrow$ \\
\hline$\checkmark$ & $19 / \pi$ & $r \cdot l \cdot \Delta$ & $r \cdot / 1$ & $r \Delta / \Lambda$ & $\cdot / \cdot r \Delta$ & $\downarrow$ \\
\hline$\wedge$ & $19 / 1$ & $19 / 9$ & $r \cdot / r$ & TF/VD & $\cdot / \cdot r V$ & $\downarrow$ \\
\hline 9 & $19 / 1$ & $19 / 9$ & $r \cdot / q$ & $r F / V D$ & $\cdot / \cdot r V$ & $\downarrow$ \\
\hline 1. & $1 N / \Delta$ & $11 / 90$ & $r \cdot r$ & $r F / q$ & $\cdot|\cdot r|$ & $\downarrow$ \\
\hline 11 & $19 / 1$ & $19 / 9$ & $r \cdot / l$ & $r \Delta / V$ & $\cdot / \cdot r k$ & $\downarrow$ \\
\hline ir & $19 / r$ & $r \mid / T 1$ & $19 / V$ & TV/TT & $\cdot / \cdot \vee \wedge$ & $\downarrow$ \\
\hline ТCC 35556 & $19 / 4$ & $T r / D$ & $19 / 0$ & $r V / q$ & . & $\downarrow$ \\
\hline
\end{tabular}

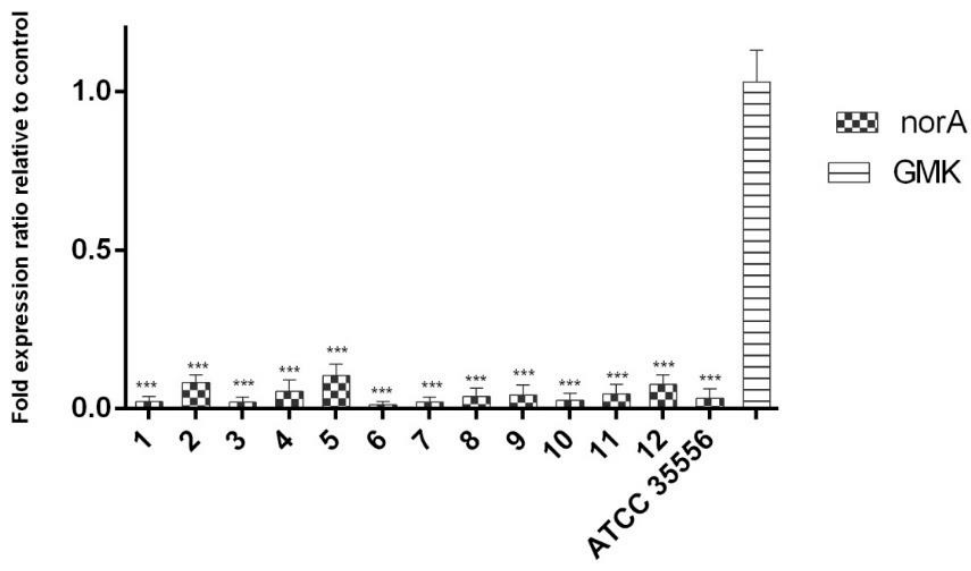

شكل r. بيان زن norA در سويههاى تيمارشده با عصاره.

افلاكس norA و norC و norC سويههاى مقاوم به دارو يافت

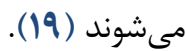

يكى از مكانيسمهاى مهم مقاومت آنتىبيوتيكى در باكترى

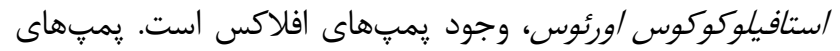


گياهان بهعنوان يك جايكزين براى آنتىبيوتيكها مورد توجه بسيار

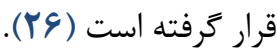

از اينرو در اين تحقيق از گياه A. ciniformis استفاده شد تا نقش آن در كاهش بيان زن norA كه يكى از زن آنهاى مههم در ايجاد

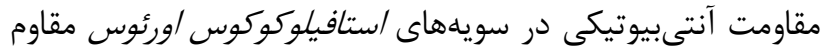
به سييروفلوكساسين است، مورد بررسى قرار كَيرد. نتايج مطالعه ما نشان داد كه عصاره كَياه A. ciniformis قادر به كاهش بيان خشمخير زن norA در سويههاى مقاوم به دايه

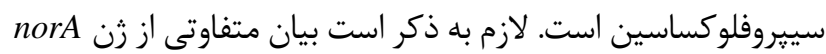
در سويههاى مقاوم ديده شد و در سويههاى مقاومتر كاهش بيان نسبى بيشترى از زن norA مشاهده شد.

تفاوت در تاثير عصارههاى كياهى بر باكترىها به عوامل مختلف وابسته است كه از آن ميان مى توان به منطقه جغرافيايى باني رويش، رقمم سن كياه، روش خشك كردن، روش استخراج تركيبات موثر، نوع حلال، غلظت عصاره و نوع محيط كشت اشاره نمود. بهطور

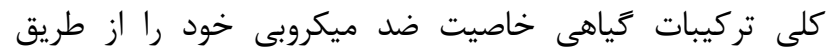
سازوكارهائى جون تجزيه ديواره سلولى، افزايش اسيديته سيتوزولى،

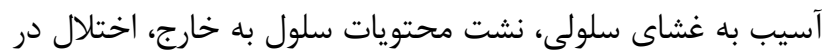

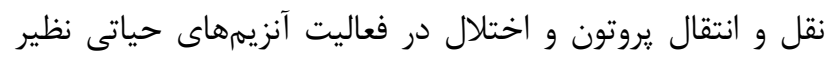
ATpase و جلوكيرى از متابوليسم باكترى اعمال مى كنند (YV) استفاده از عصاره هاى گياهى بعلت يتانسيل ضد باكتريايى كه دارند، مىتواند يك روش موثر، كمهزينه و قابل دسترس جهت

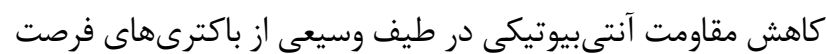

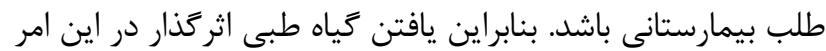

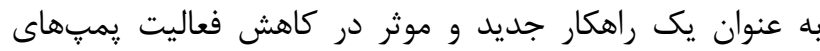

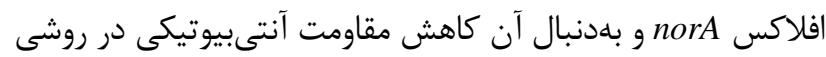

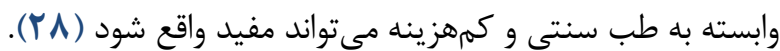
مطالعات مختلفى در زمينه بررسى تاثير تركيبات خاص بر روى بيان زنهاى يمٍهاى افلاكس انجام شده است. فلاوينوئيد sarothrin استخراج شده از برك و كل orientalis سبب مهار فعاليت يمب افلاكس norA و مانع از رشد (Y^) kalia capsaicin (8-methyl-N-vanillyl-6-nonenamide) S. aureus SA-1199B (NorA دماركننده "يمب norA SA-K1758 (norA , SA-1199 (wild-type) ، overproducing)
بر اساس ترادف و شباهت اسيدهاى آمينه، ينج گروه اصلى براى

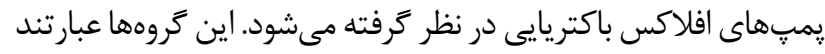
Major ، زخانواده (RNistance-Nodulation Division (RND) Small Multidrug Resistance ،Facilitator Super Family (MFS) ،Multidrug and Toxic Compound Extrusion (MATE) ،(SMR) ATP Binding Cassette مرتبط با گروههاى RND يا MFS هستند كه با آزادسازى انرزى نيرو

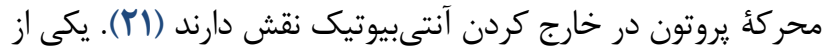
سيستمهاى مهم افلاكس در استافيلوكوكوس اورئوس سيستم

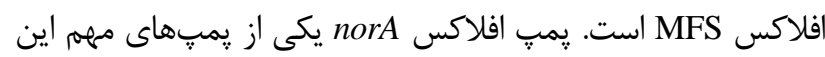

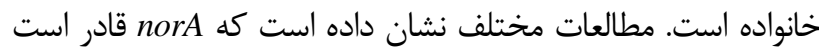
تركيبات مختلفى مانند فلئوروكينولونهاى هيدروفوب از قبيل نورفلوكساسين، سييروفلوكساسين، اتيديوم برومايد را به خارج سلول يُمٍ كند (Tr). هم جنين اثبات شده است كه سلول باكترى داراى

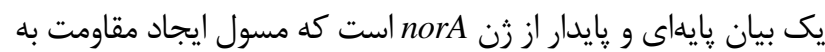
تركيبات آنتىبيوتيكى است. ارتباط مستقيمى بين افزايش بيان بمِ

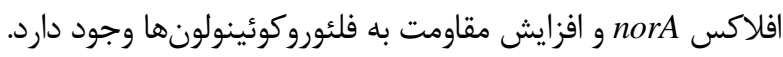
ثابت شده است كه ايجاد جهش در زن norA مىتواند سبب بروز بيان دايمى و فعال شدن اين يمب شود. بلهورى كه اين

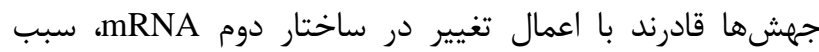
افزايش نيمةٔ عمر آن و همجنين كاهش حساسيت به به آنزيم RNases

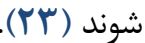

نشان داده شده است كه يمب افلاكس norA در ايجاد مقاومت به سييروفلوكساسين در سويه بالينى /ستافيلوكوكوس /ورئوس نقش

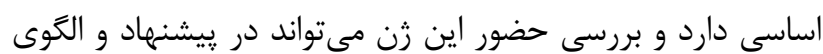

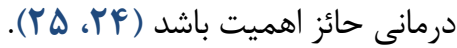

استفاده از آنتىبيوتيكها در حذف عامل ميكروبى بسيار مفيد هستند. اما در سالهاى اخير مقاومت باكترىها به آنتىبيوتيكهاى بيكياي مختلف در حال افزايش است. از سوى ديكر خود آنتىبيوتيك علاوه بر اثر كشندگى بر روى باكترىهاى مهاجم بر روى فلور نرمال بدن

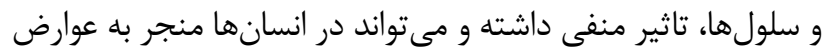

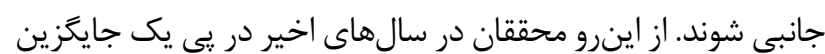

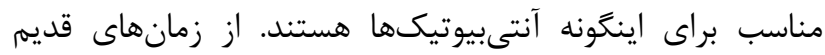
كياهان دارويى بلعنوان منابع مهم متابوليتهاى ثانويه (ترينوئيد،

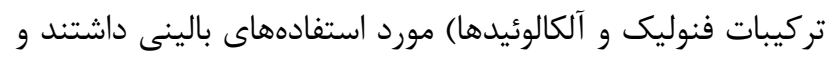

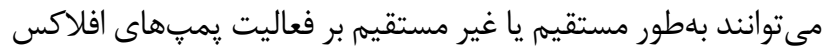

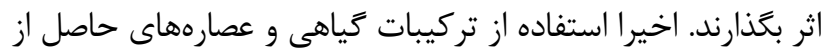




$$
\begin{aligned}
& \text { نتايج اين مطالعه هم همراستا با مطالعات ديخر بيانكر اين بود }
\end{aligned}
$$

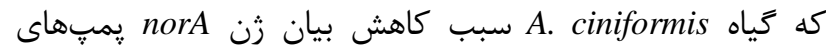

$$
\begin{aligned}
& \text { افلاكس در باكترى /ستافيلوكوكوس /ورئوس شد. كاهش بيان زن } \\
& \text { norA }
\end{aligned}
$$

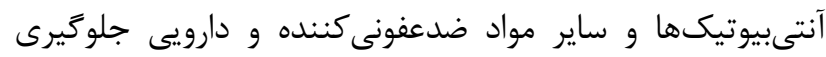

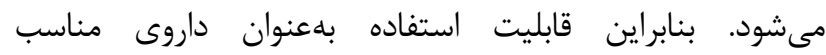

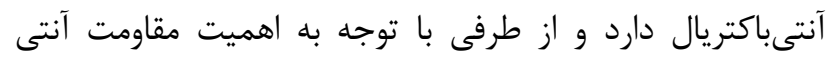

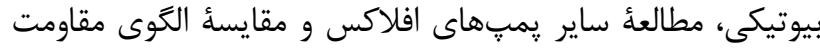

$$
\begin{aligned}
& \text { آنتىبيوتيكى ييشنهاد مىشود. } \\
& \text { سياسگزارى }
\end{aligned}
$$$$
\text { از دانشكاه آزاد اسلامى واحد يرند و دكتر بازركان تشكر و }
$$

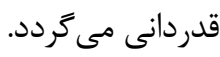

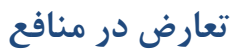

در انجام مطالعهُ حاضر، نويسندكان هيجَّونه تضاد منافعى

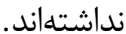

$$
\text { منابع مالى مالى اين تحقيق توسط، نويسندكان تامين شده است. }
$$

\section{Referance}

1. Kluytmans J, Van Belkum A, Verbrugh H. Nasal carriage of Staphylococcus aureus: epidemiology, underlying mechanisms, and associated risks. Clinical microbiology reviews.

1997;10(3):505-20.

[DOI:10.1128/CMR.10.3.505]

2. Corredor Arias LF, Espinal L, Samara J, Moncayo Ortiz JI, Santacruz Ibarra JJ, Álvarez Aldana A. Relationship between super antigenicity, antimicrobial resistance and origin of Staphylococcus aureus isolated. Colombia Médica.

2016;47(1):15-20 [DOI:10.25100/cm.v47i1.1818]

3. Hefzy EM, Hassan GM, Abd El Reheem F. Detection of Panton-Valentine leukocidin-positive methicillin-resistant Staphylococcus aureus nasal carriage among Egyptian health care workers. Surgical infections. 2016 1;17(3):369-75. [DOI:10.1089/sur.2015.192] [PMID]

4. Petrović-Jeremić L, Kuljić-Kapulica N, Ristanović E, Jošić D, Lepšanović Z. Prevalence of Panton-Valentine leukocidin genes in community-associated methicillinresistant Staphylococcus aureus in the District of Pomoravlje. Vojnosanitetski pregled. 2016;73(3):256-60. [DOI:10.2298/VSP140715003P] knockout)

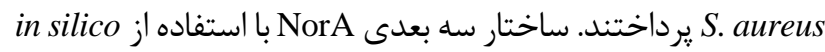

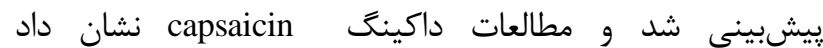
S. aureus سبي كاهش MIC سيروفلوكساسين در capsaicin كان S. مىشود. بطوريكه سبب افزايش حساسيت SA-1199B, SA-1199

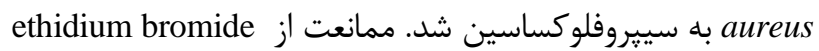
NorA-overproducing S. aureus SA-1199B توسط ا را به عنوان مهاركننده يمب NorA efflux capsaicin اين مطالعه براى اولين بار نشان داده است كه capsaicin نه تنها سبب كاهش فعاليت يمب افلاكس مى شود بلكه سبب كاهش حمله استافيلوكوكها به ماكروفازها نيز مىشود (9 (؟).

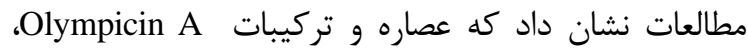

5,7-dihydroxy-6-(2-methylbutanoyl)-8-(3-methylbut-2g Karavilagenin $\mathrm{C}$ ،enyl)-4-phenyl- 2H-chromen-2-one Boeravinone B ، Ailanthoidiol

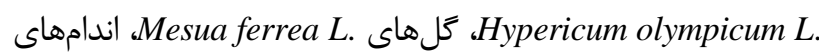
هوايى .Momordica balsamina Lanthoxylum capense ريشه Boerhavia diffusa وبب مهار و كاهش فعاليت پٍِ افلاكس norA Efflux pump inhibitor

5. Firsov AA, Smirnova MV, Strukova EN, Vostrov SN, Portnoy YA, Zinner SH. Enrichment of resistant Staphylococcus aureus at ciprofloxacin concentrations simulated within the mutant selection window: bolus versus continuous infusion. International journal of antimicrobial agents. 2008 1;32(6):488-93. [DOI:10.1016/j.ijantimicag.2008.06.031] [PMID]

6. S. Maisnier-Patin and D. I. Andersson; WHO Regional Committee for Europe. European strategic action plan on antibiotic resistance. Res. Microbiol. 2004, 155,360-369; Copenhagen. 2011. [DOI:10.1016/.r.esmic.2004.01.019] [PMID]

7. American Academy of Microbiology. Antibiotic resistance: an ecological perspective on an old problem. Washington DC.2009.

8. Kumar A, Schweizer HP. Bacterial resistance to antibiotics: active efflux and reduced uptake. Advanced drug delivery reviews. 2005;57(10):1486-513. [DOI:10.1016/j.addr.2005.04.004] [PMID]

9. Stavri M, Piddock LJ, Gibbons S. Bacterial efflux pump inhibitors from natural sources. Journal of antimicrobial 
chemotherapy.

2007;59(6):1247-60. [DOI:10.1093/jac/dk1460] [PMID]

10. Tegos GP, Masago K, Aziz F, Higginbotham A, Stermitz FR, Hamblin MR. Inhibitors of bacterial multidrug efflux pumps potentiate antimicrobial photoinactivation. Antimicrobial agents and chemotherapy. 2008 1;52(9):3202-9. [DOI:10.1128/AAC.00006-08] [PMID] [PMCID]

11. De Kievit TR, Parkins MD, Gillis RJ, Srikumar R, Ceri H, Poole K, Iglewski BH, Storey DG. Multidrug efflux pumps: expression patterns and contribution to antibiotic resistance in Pseudomonas aeruginosa biofilms. Antimicrobial agents and chemotherapy. 2001;45(6):1761-70. [DOI:10.1128/AAC.45.6.17611770.2001] [PMID] [PMCID]

12. Poole K. Multidrug efflux pumps and antimicrobial resistance in Pseudomonas aeruginosa and related organisms. Journal of molecular microbiology and biotechnology. 2001;3(2):255-64.

13. Sierra JM, Ruiz J, Jimenez De Anta MT, Vila J. Prevalence of two different genes encoding NorA in 23 clinical strains of Staphylococcus aureus. Journal of Antimicrobial Chemotherapy. 2000;46(1):145-6. [DOI:10.1093/jac/46.1.145] [PMID]

14. Motallebi M, Jabalameli F, Asadollahi K, Taherikalani M, Emaneini M. Spreading of genes encoding enterotoxins, haemolysins, adhesin and biofilm among methicillin resistant Staphylococcus aureus strains with staphylococcal cassette chromosome mec type IIIA isolated from burn patients. Microbial pathogenesis. 2016;97:34-7. [DOI:10.1016/j.micpath.2016.05.017] [PMID]

15. Simoes M, Bennett RN, Rosa EA. Understanding antimicrobial activities of phytochemicals against multidrug resistant bacteria and biofilms. Natural product reports. 2009;26(6):746-57. [DOI:10.1039/b821648g] [PMID]

16. Schelz Z, Hohmann J and Molnar J. Ethnomedicine: A Source of Complementary Therapeutics. ed. D. Chattopadhyay.Research Signpost.1st edn. 2010; 6:179201.

17. Sibanda T, Okoh AI. The challenges of overcoming antibiotic resistance: Plant extracts as potential sources of antimicrobial and resistance modifying agents. African Journal of Biotechnology. 2007;6(25).

18. Zahmatkesh H, Alsadat M, Laripoor M, Mirzaie A, Ashrafi F. Prevalence of norA and norB efflux pump genes in clinical isolates of Staphylococcus aureus and their contribution in ciprofloxacin resistance. Iranian Journal of Medical Microbiology. 2016;10(5):20-30.

19. Stutz K, Stephan R, Tasara T. SpA, ClfA, and FnbA genetic variations lead to Staphaurex test-negative phenotypes in bovine mastitis Staphylococcus aureus isolates. Journal of clinical microbiology. 2011;49(2):63846. [DOI:10.1128/JCM.01148-10] [PMID] [PMCID]

20. Kosmidis C, Schindler BD, Jacinto PL, Patel D, Bains K, Seo SM, et al. Expression of multidrug resistance efflux pump genes in clinical and environmental isolates of Staphylococcus aureus. International journal of antimicrobial agents. 2012;40(3):204-9. [DOI:10.1016/j.ijantimicag.2012.04.014] [PMID]

21. Paulsen IT, Lewis K. Microbial multidrug efflux. Horizon Scientific. 2002; 3(2): 143-144.

22. Li XZ, Nikaido H. Efflux-mediated drug resistance in bacteria. Drugs. 2009;69(12):1555-623. [DOI:10.2165/11317030-000000000-00000] [PMID] [PMCID]

23. Kumar A, Schweizer HP. Bacterial resistance to antibiotics: active efflux and reduced uptake. Advanced drug delivery reviews. 2005;57(10):1486-513. [DOI:10.1016/j.addr.2005.04.004] [PMID]

24. Zahmatkesh H, Alsadat M, Laripoor M, Mirzaie A, Ashrafi F. Prevalence of norA and norB efflux pump genes in clinical isolates of Staphylococcus aureus and their contribution in ciprofloxacin resistance. Iranian Journal of Medical Microbiology. 2016;10(5):2030.Iranian.

25. KAZEMI SS, NEMATI MF, MIRZAIE A, ASHRAFI F. Antibiotic resistance assessment, and genotypic and phenotypic detection of norA efflux pump in methicillin and ciprofloxacin resistant Staphylococcus aureus isolates.Pump in Methicillin and Ciprofloxacin Staphylococcus Aureus Strains. Journal of Microbial World. 2017; 9(4): 286-296.Iranian.

26. Seukep AJ, Kuete V, Nahar L, Sarker SD, Guo M. Plantderived secondary metabolites as the main source of efflux pump inhibitors and methods for identification. Journal of Pharmaceutical Analysis. Available online 5 November 2019. in press [DOI:10.1016/j.jpha.2019.11.002]

27. Holler JG, Christensen SB, Slotved HC, Rasmussen HB, Gúzman A, Olsen CE,et al. Novel inhibitory activity of the Staphylococcus aureus NorA efflux pump by a kaempferol rhamnoside isolated from Persea lingue Nees. Journal of Antimicrobial Chemotherapy. 2012;67(5):1138-44. [DOI:10.1093/jac/dks005] [PMID]

28. Bame JR, Graf TN, Junio HA, Bussey IIII RO, Jarmusch SA, El-Elimat T,et al. Sarothrin from Alkanna orientalis is an antimicrobial agent and efflux pump inhibitor. Planta Med. 2013;79(5):327-9. doi: 10.1055/s-0032-1328259. [DOI:10.1055/s-0032-1328259] [PMID] [PMCID]

29. Kalia NP, Mahajan P, Mehra R, Nargotra A, Sharma JP, Koul S, et al. Capsaicin, a novel inhibitor of the NorA efflux pump, reduces the intracellular invasion of Staphylococcus aureus. Journal of antimicrobial chemotherapy. 2012;67(10):2401-8. [DOI:10.1093/jac/dks232] [PMID] 
30. Shiu WK, Malkinson JP, Rahman MM, Curry J, Stapleton $\mathrm{P}$, Gunaratnam M,et al. A new plant-derived antibacterial is an inhibitor of efflux pumps in Staphylococcus aureus. International journal of antimicrobial agents. 2013;42(6):513-8.

[DOI:10.1016/j.ijantimicag.2013.08.007] [PMID]

31. Roy S, Kumari N, Pahwa S, Agrahari U, Bhutani K, Jachak S, Newman D NorA efflux pump inhibitory activity of coumarins from Mesua ferrea. Fitoterapia. 2013; 90:140-150. [DOI:10.1016/j.fitote.2013.07.015] [PMID]

32. Ramalhete C, Spengler G, Martins A, Martins M, Viveiros M, Mulhovo S, Ferreira M, Amaral L Inhibition of efflux pumps in meticillin-resistant Staphylococcus aureus and Enterococcus faecalis resistant strains by triterpenoids from Momordica balsamina. Int J Antimicrob Agents. 2011; 37:70-74. [DOI:10.1016/j.ijantimicag.2010.09.011] [PMID]

33. Cabral V, Luo X, Junqueira E, Costa S, Mulhovo S, Duarte A, Couto I, Viveiros M, Ferreira M. Enhancing activity of antibiotics against Staphylococcus aureus: Zanthoxylum capense constituents and derivatives. Phytomedicine. 2015; 22:469-476. [DOI:10.1016/j.phymed.2015.02.003] [PMID]

34. Singh S, Kalia NP, Joshi P, Kumar A, Sharma PR, Kumar A, Bharate SB, Khan IA . Boeravinone B, A Novel Dual Inhibitor of NorA Bacterial Efflux Pump of Staphylococcus aureus and Human P-Glycoprotein, Reduces the Biofilm Formation and Intracellular Invasion of Bacteria. Front Microbiol. 2017;8:1868. [DOI:10.3389/fmicb.2017.01868] [PMID] [PMCID] 